\title{
Proses Distribusi Dan Strategi Optimasi Pengiriman Paket Dan Dokumen Dalam Negeri Pada Kantor Pos Besar Surabaya Utara 60000
}

\author{
Distribution Process And Optimization Strategy For Delivering \\ Domestic Package And Document At North Surabaya Post Office \\ 60000
}

\author{
Amanda Ristriana Pattisinai ${ }^{1, a)}$ \& Muniatun Khoirun Nisa ${ }^{2, b)}$ \\ 1) Program Studi Transportasi, Teknik Sipil, Universitas Negeri Surabaya, (UNESA), Surabaya. \\ 2) Program Studi Transportasi, Teknik Sipil, Universitas Negeri Surabaya, (UNESA), Surabaya.
}

Koresponden : ${ }^{a}$ amandaristriana@ unesa.ac.id \& ${ }^{b}$ muminatunkhoirunn@gmail.com

\begin{abstract}
ABSTRAK
Perusahaan milik pemerintah tidak bisa berkembang dengan optimal beberapa dekade ini. Salah satu infrastruktur logistik yang mengalami kemunduran dalam melakukan managemen perusahaannya adalah PT. POS Indonesia. Maka dibutuhkan pengamatan lebih lanjut dalam proses distribusi dan pengiriman paket dan dokumen dalam negeri sehingga didapatkan permasalahan yang kemudian dapat dirumuskan strategi pengembangannya dikemudian hari. Penelusuran mengenai proses distribusi dan strategi optimalisasi pengiriman paket dan dokumen dilakukan dengan menggunakan pendekatan primer dan sekunder. Hingga didapatkan bahwa keempat tahapan distribusinya masih belum efisien, seperti proses collecting, processing, transporting, dan delivery yang lebih banyak mengandalkan tenaga manusia dalam prosesnya dibandingkan software serta peralatan modern yang dapat mengurangi kemungkinan barang hilang, rusak, dan tidak terkirimkan tepat waktu ke tangan konsumen.
\end{abstract}

Kata Kunci : manajemen fasilitas, distribusi, pengiriman barang dan dokumen, strategi optimalisasi, POS Indonesia

\section{PENDAHULUAN}

Manajemen aset merupakan proses pengorganisasian, perencanaan dan pengawasan terhadap pembelian, penggunaan, perawatan, perbaikan, dan/atau penghapusan aset fisik untuk mengoptimalkan potensi service delivery dan meminimalkan resiko atau cost yang berkaitan dengan usia hidup aset dengan menggunakan aset-aset intangible seperti aplikasi pengambilan keputusan berbasis knowledge dan proses bisnis (Ouertani, 2008). Sementara itu, manajemen aset seringkali dianggap sebagai persoalan teknis sehingga seringkali permasalahan didalamnya hanya diselesaikan dengan pendekatan taktis saja (Giglio, 2018). Hal ini menyebabkan beberapa perusahaan milik pemerintah tidak bisa berkembang dengan optimal beberapa dekade ini. Salah satu infrastruktur logistik yang mengalami kemunduran dalam melakukan management perusahaannya adalah PT. POS Indonesia. Hal ini dapat dilihat dari preferensi masyarakat dalam menggunakan jasa pengiriman lain yang lebih murah dan cepat dibandingkan dengan menggunakan layanan PT POS Indonesia (Wahyuningsih, 2014). 
PT. Pos Indonesia merupakan satu-satunya perusahaan jasa pengiriman barang baik paket maupun dokumen nasioanl dijamannya yang berdiri sejak tahun 1746 (www.posindonesia.co.id diakses tanggal 11 Agustus 2018). Seiring dengan perkembangan jaman saat ini, banyak bermunculan perusahaan jasa pengiriman swasta sehingga timbul persaingan antar perusahaan logistik, baik dari segi pelayanan, keandalan, jangkauan pengiriman maupun harga. Hal ini merupakan efek langsung dari berkembangnya online shopping yang berkembang di Indonesia sehingga memacu geliat positif bagi lahirnya bisnis pengiriman barang yang kompetitif (Siringoringo, 2013).

Menurut laporan TechinAsia dalam Tikno (2017) pada 2015, lebih dari 72 juta orang Indonesia terdaftar sebagai pengguna internet aktif. Sekitar $18 \%$ dan $11 \%$ melakukan searching di website melalui desktop dan perangkat seluler masing-masing sebelum membeli secara online. Zhang (2018) dan Hayashi (2018) menyatakan bahwa sebanyak $80 \%$ dari pengguna internet yang melakukan searching di internet melakukan pembelian melalui online shopping. Sehingga dapat disimpulkan bahwa penggunaan internet cenderung online shopping dan pengusaha online shop akan melakukan pengiriman barang sesudahnya.

Tingginya jumlah pengiriman barang disebabkan oleh banyaknya kebutuhan masyarakat untuk mengirimkan barang (Fu (2007), Nakada (1994), Sasaki (2016) dan Nemoto (2012)), baik paket maupun dokumen tanpa harus pergi ke tempat tujuan, meningkatkan volume kiriman barang pada Kantor Pos Surabaya PC Surabaya 60900. Berdasarkan data dari marketing Kantor Pos PC Surabaya 60900, pada periode Januari - Desember 2016 saja total pengiriman barang mencapai 5.945.062 item. Hal ini menunjukkan PT POS Indonesia masih memegang peranan yang sangat penting dalam hal pengiriman barang maupun dokumen di dalam negeri baik dalam jumlah kecil maupun besar. Namun demikian, pengiriman melalui PT. POS Indonesia dinilai masyarakat masih membutuhkan penambahan kualitas pelayanan dikemudian hari, terkait dengan quality service dan keandalan (Rofiah, 2017).

Dalam proses pendistribusian dalam negeri PT. Pos Indonesia melakukan distribusi barang baik paket maupun dokumen ke berbagai daerah di Indonesia dilakukan di Kantor Pos Surabaya 60000 sebagai kantor pusat di kota Surabaya Utara. Kantor pos ini berperan dalam proses pendistribusian paket maupun dokumen di Kota Surabaya khususnya Surabaya utara dan diproses lebih lanjut disana. Proses pengiriman barang dan mekanisme distribusi memegang peranan penting bagi waktu dan kondisi barang agar barang bisa sampai pada waktu dan tempat yang tepat (NohraHaddad, 2018). Kesalahan dalam proses distribusi dapat juga berpengaruh pada meningkatnya harga produsi dan meningkatkan waktu pengiriman. Hal ini tentunya berpengaruh pada kualitas barang dan kepercayaan konsumen terhadap kehandalan PT. POS Indoensia sebagai penyedia layanan distribusi logistik di Indonesia. Oleh karena itu dilakukan penelusuran mengenai Optimasi Proses Distribusi Paket dan Dokumen di Kantor Pos Surabaya 60000.

\section{STUDI PUSTAKA}

\section{Definisi Distribusi Barang}

Kegiatan pendistribusian merupakan bagian penting dalam bidang logistik. Menurut Tjiptono dan Chandra (2008) distribusi adalah kegiatan pemasaran yang berusaha memperlancar dan mempermudah penyampaian barang dan jasa dari produsen kepada konsumen. PT. Pos Indonesia pada bidang logistik memiliki layanan untuk pengiriman paket, dokumen serta uang dan berdasarkan Peraturan Pemerintah No 15 tahun 2013 Standar Pelayanan untuk layanan pos komersial salah satunya yaitu meliputi kepastian waktu layanan, namun pada kenyataannya masih ada pengiriman barang yang dikembalikan lagi disebabkan karena gagal $X$-ray ataupun barang yang pengirimannya salah alamat tujuan yang menyebabkan barang tidak sampai tempa tujuan sesuai dengan waktu yang telah ditetapkan. 


\section{Pengangkutan Barang}

Menurut Keputusan Direktorat Jendral Perhubungan Darat Nomor 727/ AJ.307/DRJD/2004 tentang Pedoman Teknis Penyelenggaraan Angkutan Barang Umum Di Jalan, Pengangkutan barang umum di jalan adalah satu cara penyelenggaraan angkutan untuk memindahkan barang umum dari suatu tempat ke tempat lain dengan menggunakan mobil barang. Barang umum sebagaimana dimaksud adalah bahan atau benda selain dari bahan berbahaya, barang khusus, peti kemas dan alat berat yang terdiri dari :

1. Muatan umum

2. Muatan logam

3. Muatan kayu

4. Muatan yang dimasukkan ke palet

5. Pengangkutan kendaraan dengan cara bertingkat

6. Kendaraan dengan tutup gorden samping

7. Kaca lembaran

\section{Tata Cara Pengangkutan}

Menurut Keputusan Direktorat Jendral Perhubungan Darat Nomor 727/ AJ.307/DRJD/2004 tentang Pedoman Teknis Penyelenggaraan Angkutan Barang Umum Di Jalan, Beberapa hal yang harus diperhatikan dalam pengangkutan barang umum yaitu :

1. Keselamatan muatan kendaraan.

2. Muatan harus diangkut kendaraan dalam kondisi aman untuk melindungi orang-orang yang terlibat dalam pemuatan, pembongkaran (muatan) dan mengendarai kendaraan, serta pemakai jalan lainnya dan para pejalan kaki.

3. Pemuatan dan pembongkaran harus memperhatikan ketentuan Kesehatan dan Keselamatan Kerja.

4. Pemuatan dan pembongkaran harus dilakukan oleh orang-orang yang terlatih yang mengetahui resiko yang dikandungnya, termasuk pengemudi juga harus mengetahui resiko tambahan dari muatan, atau sebagian muatan, yang bergerak saat kendaraan dikemudikan.

5. Semua peralatatan pada kendaraan barang harus digunakan sesuai petunjuk penggunaan dari pabrik sehingga tidak membahayakan bagi para pengguna jalan lainnya serta pejalan kaki.

6. Muatan Tinggi :

a. Perhatian khusus harus diberikan terhadap bahaya muatan tinggi yang mungkin harus melewati bawah jembatan atau bangunan lain di sepanjang jalan. Jembatan dapat dihantam kendaraan barang yang bermuatan terlalu tinggi untuk melewati di bagian bawah jembatan. Hal ini dapat mengakibatkan pengemudi kendaraan dan orang lain tewas atau lukan-luka. Setiap tubrukan pada jembatan kereta api berpotensi mengeluarkan rel, yang bisa menyebabkan kereta api tergelincir keluar rel dan kemungkinan kecelakaan kereta api serius.

b. Semua kendaraan dengan ketinggian keseluruhan saat melakukan perjalanan di atas 3 meter harus memiliki tinggi maksimum kendaraan dalam kaki dan inci yang ditampilkan di dalam kabin sehingga jelas terlihat oleh pengemudi.

c. Setiap kendaraan yang terpasang dengan peralatan tingkat tinggiyang mampu melampaui ketinggian 3 meter harus dipasang dengan peralatan peringatan visual.

\section{Dokumen Angkutan}

Dalam pengiriman barang dibutuhkan beberapa dokumen dalam pengangkutan yang disebut transportation documents, Dibawah ini diberikan beberapa contoh dokumen dalam transportasi menurut Salim (1993:40) sebagai berikut : 
1. Dokumen pengiriman barang

Suatu perusahaan ekspedisi yang melaksanakan pengiriman barang, menggunakan shipment documents sebagai bukti bagi si penerima barang nantinya, bahwa barangbarang tersebut telah diangkut oleh perusahaan ekspedisi.

Perusahaan pengangkutan harus bertanggung jawab untuk mengangkut barangbarang tersebut, sampai ke tempat tujuan.

2. Surat menyurat (bill of lading)

Di dalam bill of lading diadakan kontrak barang-barang yang diangkut, hal mana si pengirim barang akan menyerahkannya kepada si penerima atas dasar perjanjian yang telah dibuat. Adapun tujuan dari bill of lading adalah :

a. Si penerima akan menerima barang dalam kondisi baik.

b. Pengangkutan berdasar isi kontrak yang telah dibuat.

c. Semua transaksi dalam pengangkutan dijelaskan dalam perjanjian. Jenis bill of lading dapat dibedakan yaitu :

a. Bill of lading yang langsung.

b. Bill of lading berdasarkan order.

c. Surat-surat muatan (Cargo).

Selain itu, transportasi mengunakan pula "dokumen pendukung" (supporting document) yang didalamnya memuat : kapan barang tersebut tiba di tempat (tanggal dan waktu), si penerima barang dan masalah claim, bila terjadi kerugian atau kerusakan atas pengiriman barang.

3. Dokumen bagi manajemen

Dalam pengangkutan barang-barang, dikenal pula management document.

Ada beberapa jenis manajemen dokumen yaitu :

a. Kontrak

Dalam kontrak dijelaskan jangka waktu, dan asal/tujuan pengiriman barang.

b. Tarif

Untuk angkutan harus jelas tarif yang dihitung untuk pengangkutan tersebut.

c. Polis Asuransi

Selama dalam perjalanan barang-barang yang diangkut diasuransikan terdiri dari :

1) Asuransi biaya pengangkutan

2) Asuransi atas kerugian barang

3) Asuransi atas kerusakan barang-barang.

d. Biaya-biaya/ Cost \& Freight

Dalam peangkutan yang diperhitungkan adalah biaya dan uang tambang

e. Cif (Cost insurance and freight)

Selama dalam pengangkutan yang diperhitungkan adalah biaya, asuransi dan uang tambang

f. Franco gudang

Artinya si pengirim/ si penjual barang hanya bertangung jawab atas barang sampai masuk ke dalam gudang

g. Manifest

Surat muatan yang dibawah oleh nakhoda kapal memuat seluruh barang-barang dan penumpang yang diangkut.

\section{PENGUMPULAN DATA}

Metode yang digunakan pada Optimasi Proses Distribusi Paket dan Dokumen di Kantor Pos Surabaya 60000 ini adalah pengumpulan data primer terkait proses distribusi yang berlangsung di lapangan dan data sekunder terkait literatur. Pada pengumpulan data primer dilakukan pengamatan secara langsung selama 100 hari di Kantor Pos Besar Surabaya Utara 
60000 untuk mengetahui proses distribusi dari awal hingga akhir yang dijadikan acuan atau dasar dalam mengerjakan optimasi proses distribusi.

\section{PEMBAHASAN}

\section{Jenis produk pengiriman barang pada PT. Pos Indonesia kota Surabaya utara :}

Jenis Produk Pengiriman Barang pada PT Pos Indonesia Kantor Surabaya Utara terdiri dari empat jenisproduk Pengiriman Barang sebagai berikut.

\section{Pos Express}

Pos Express merupakan layanan premium milik Pos Indonesia untuk pengiriman cepat dan aman dengan jangkauan luas ke seluruh wilayah Indonesia. Menjadi pilihan tepat dan terpercaya untuk mengirim dokumen, surat, paket serta barang dagangan online.

Jaringan nasional pos express meliputi 48 kota/ kabupaten serta regional di 201 Kota atau Kabupaten yang terus dikembangkan untuk memenuhi kebutuhan dan harapan masyarakat. Pick up service disediakan bagi pengiriman pos express dalam jumlah tertentu. Jaringan nasional pos ekspress saat ini meliputi: seluruh kota di Jawa Timur. Sumatera dan Riau : Medan, Padang, Pekanbaru, Tanjungpinang, Batam, Palembang, Pangkal pinang, Bandar lampung, Jambi, Bengkulu. DKI Jakarta : Jakarta Pusat, Jakarta Barat, Jakarta Taman Fatahillah, Jakarta Selatan, Jakarta Mampang, Jakarta Timur, Jakarta Jatinegara, Jakarta Utara. Jawa Barat dan Banten : Tangerang, Ciputat, Bogor, Depok, Sawangan, Cibinong, Bekasi, Pondok Gede, Serang, Cilegon, Bandung, Cimahi, Ujungberung, Soreang, Purwakarta, Cirebon. Jawa Tengah dan Daerah Istimewa Yogyakarta: Semarang, Semarang Erlangga, Jogjakarta, Solo. Bali dan Nusa Tenggara : Denpasar, Denpasar Sanglah, Mataram Kalimantan: Banjarmasin, Balikpapan, Pontianak. Sulawesi : Makassar, Manado + jaringan regional di 106 kota di seluruh Indonesia.

Informasi tarif dan jaringan kiriman Pos Ekspress Jaminan ganti rugi atas ketepatan waktu penyerahan dan keamanan isi kiriman, aman terjaga, karena diasuransikan sepenuhnya oleh PT Pos Indonesia. Jaringan pos express terintegrasi dan terkoneksi dengan sistem teknologi informasi yang memungkinkan status kiriman lebih mudah dilacak dan diketahui.

2. Pos Kilat Khusus

Pos Kilat Khusus merupakan layanan milik Pos Indonesia untuk pengiriman aman dan cepat dengan jangkauan luas ke seluruh wilayah Indonesia. Menjadi pilihan tepat dan terpercaya untuk mengirim dokumen, surat, paket serta barang dagangan online.

Informasi tarif dan jaringan kiriman poskilat khusus. Jaminan ganti rugi atas ketepatan waktu penyerahan dan keamanan isi kiriman Jaringan poskilat khusus sudah terintegrasi dan terkoneksi dengan system teknologi informasi yang memungkinkan status kiriman lebih mudah dilacak dan diketahui. Jaringan pengiriman poskilat khusus menjangkau seluruh kota/ kabupaten di Indonesia.

3. Paket Pos Biasa

Paket pos Biasa adalah layanan pengiriman paket dengan tarif paling ekonomis. Pengiriman barang melalui Paketpos Biasa menjangkau seluruh pelosok Indonesia.

4. Surat Pos Biasa

Surat Pos Biasa (Standar) merupakan Layanan pengiriman dokumen, surat, dan kartupos untuk semua lapisan masyarakat menggunakan prangko sesuai dengan tarif yang berlaku untuk wilayah tertentu. Kemudahan akses dan jangkauan pelayanan. Surat Pos Biasa dapat dikirim melalui loket Kantor Pos mana saja. 


\section{Karakteristik dan keunggulan produk pengiriman barang PT. Pos Indonesia :}

Karakteristik dan Keunggulan keempat Jenis Produk Pengiriman Barang bisa disampaikan sebagai berikut.

\section{Pos Express}

a. Karakteristik

- Berat maksimal kiriman s.d $50 \mathrm{~kg}$. Ukuran dimensi maksimal kiriman, baik yang berbentuk kotak, gulungan, dan yang tidak beraturan adalah: Ukuran maksimal (berbentuk kotak/gulungan), sebagai berikut: panjang +2 (Lebar + Tinggi $)=400$ $\mathrm{cm}$, dimensi terpanjang maksimal $150 \mathrm{~cm}$.

- Tarif ditentukan dengan cara sebagai berikut :

a) Mempergunakan berat kiriman aktual (Actual Weight)

b) Mempergunakan perhitungan volumetric untuk kotak/gulungan yang dikonversikan menjadi berat dengan rumusan sebagai berikut: (Panjang $\mathrm{x}$ Lebar x Tinggi x $1 \mathrm{~kg}$ ) : 6.000

- Penyerahan kiriman dapat disesuaikan dengan permintaan pelanggan, yaitu :

a) Kiriman diantar ke alamat penerima

b) Kiriman bisa diambil di Kantorpos tujuan

- Standar Waktu Penyerahan (SWP) H+1hari.

b. Keunggulan

- Layanan premium yang tersedia di semua Kantorpos seluruh Indonesia

- Waktu tempuh kiriman maksimal sehari sampai sejak barang diposkan

- Tarif kompetitif

- Jaminan kehilangan/kerusakan kiriman diberikan ganti rugi

- Jejak lacak status kiriman melalui: www.posindonesia.co.id atauHaloPOS 161

- Fasilitas jemput kiriman untuk pelanggan khusus.

\section{Pos Kilat Khusus}

a. Karakteristik :

- Berat maksimal kiriman s.d 50 kg. Ukuran dimensi maksimal kiriman, baik yang berbentuk kotak, gulungan, dan yang tidak beraturan adalah: Ukuran maksimal (berbentuk kotak/gulungan), sebagai berikut: Panjang $+2($ Lebar + Tinggi $)=400$ $\mathrm{cm}$, dimensi terpanjang maksimal $150 \mathrm{~cm}$.

- Tarif ditentukan dengan cara sebagai berikut :

a) Mempergunakan berat kiriman aktual (Actual Weight)

b) Mempergunakan perhitungan volumetrik untuk kotak/gulungan yang dikonversikan menjadi berat dengan rumusan sebagai berikut: (Panjang $\mathrm{x}$ Lebar x Tinggi x $1 \mathrm{~kg}$ ) : 6.000

- Penyerahan kiriman paket pos dapat disesuaikan dengan permintaan permintaan pelanggan, yaitu :

a) Kiriman diantar kepada alamat penerima

b) Kiriman diambil di kantor pos tujuan

- Standar Waktu Penyerahan (SWP) H+2 s.d H+9 hari

b. Keunggulan :

- Layanan tersedia di semua Kantorpos seluruh Indonesia 
- Jaringan terluas ke seluruh Indonesia

- Tarif lebih hemat dan kompetitif

- Jaminan kehilangan/kerusakan kiriman diberikan ganti rugi

- Jejak lacak status kiriman melalui: www.posindonesia.co.id atau Halo POS 161

- Fasilitas jemput kiriman untuk pelanggan khusus.

\section{Surat Pos Biasa (Standar)}

a. Karakteristik :

- Berat maksimum $2 \mathrm{~kg}$

- Cara pelunasan dengan menggunakan prangko sesuai dengan tarif yang berlaku

- Tidak disediakan nomor resi untuk lacak kiriman

- Standar Waktu Penyerahan (SWP) H+14 hari

b. Keunggulan :

- Jaringan nasional terluas hingga ke seluruh wilayah Indonesia

- Kemudahan akses dan jangkauan pelayanan

- Memiliki tarif ekonomis.

\section{Ketentuan kiriman barang dan tarif kiriman PT. Pos Indonesia}

Ada beberapa barang (paket) yang tidak bisa dikirim melalui jasa pengiriman kantor pos, barang yang dilarang untuk dikirim melalui layanan paket pos adalah :

- Bahan yang rentan terhadap oksidasi, seperti : bubuk pemutih, peroksidan dll.

- Accu atau baterai basah.

- Makanan basah atau berminyak.

- Benda yang dapat meledak atau menyala atau barang yang dapat terbakar sendiri seperti senjata api, peluru dan bahan peledak, mercon atau sejenisnya serta segala macam korek api dan gas pengisinya.

- Binatang hidup

- Uang logam, uang kertas bank dan surat berharga bagi pengunjuk, platina, emas atau perak yang telah dikerjakan atau belum, permata, perhiasan, dll.

- Barang yang menyinggung kesusilaan.

- Candu morfin, kokain dan obat terlarang lainnya.

- Bahan biologis yang mudah busuk dan mudah menularkan penyakit.

- Barang lainnya yang menurut peraturan perundang-undangan dinyatakan terlarang.

Tarif untuk kiriman barang pada PT. Pos Indonesia untuk paket maupun dokumen domestik ditentukan dengan cara sebagai berikut :

- Mempergunakan berat kiriman actual (Actual Weight)

- Mempergunakan perhitungan volumetrik untuk kotak/gulungan yang dikonversikan menjadi berat dengan rumusan sebagai berikut: (Panjang x Lebar x Tinggi x $1 \mathrm{~kg}$ ) : 6.000 .

- Untuk perhitungan tarif kiriman barang pada kantor pos dilakukan dengan menggunakan aplikasi I-POS (Integrated Postal Operations System). 


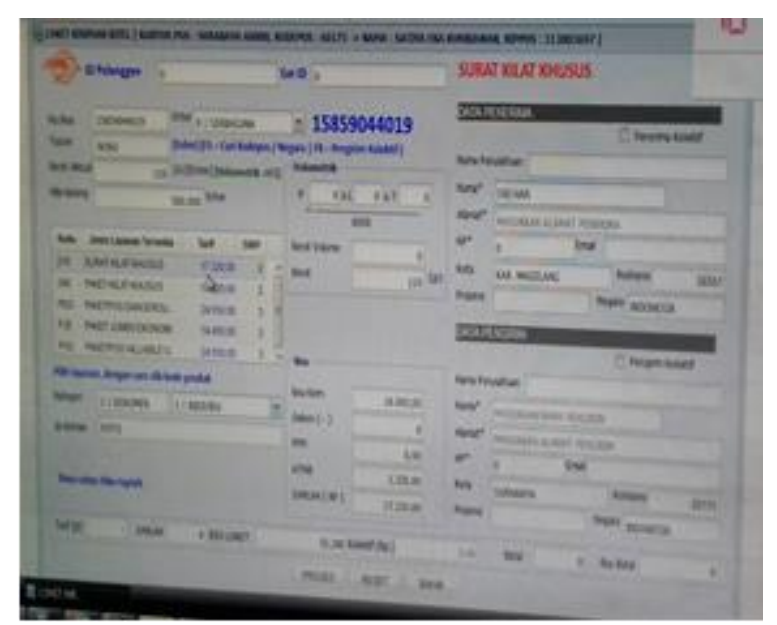

Gambar 1. Tampilan I-POS (Integrated Postal Operations System).

\section{Prosedur Pendistribusian dan Optimasi Pengiriman Paket \& Dokumen Dalam Negeri Pada Kantor Pos Surabaya 60000}

Pada Kantor Pos Surabaya 60000 proses pengiriman barang baik paket maupun dokumen terdapat empat tahap yang harus dilewati yaitu pertama proses Collecting yang dilakukan pada loket ritel, loket ritel merupakan loket yang digunakan untuk pengiriman paket \& dokumen perorangan, kedua Processing yang dilakukan pada puri, puri merupakan tempat yang digunakan untuk aktivitas processing paket \& dokumen yaitu proses sortir paket $\&$ dokumen kiriman, ketiga proses Transporting yang dilakukan pada Processing Center dan keempat proses Delivery yang dilakukan pada Delivery Center.

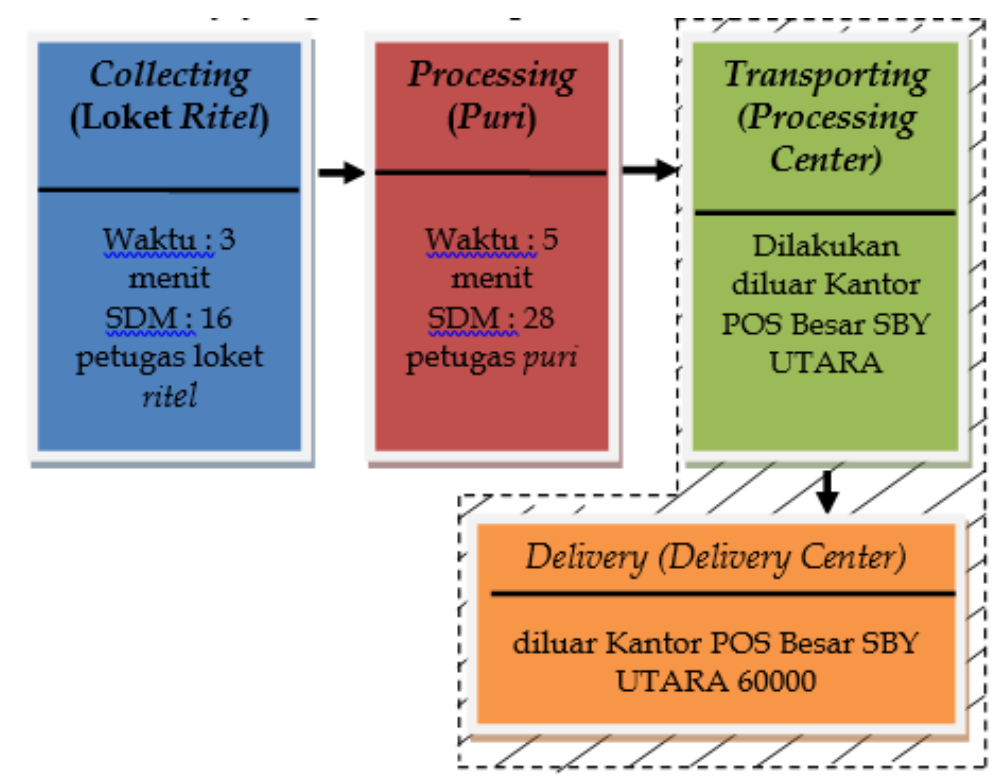

Keterangan :

Bagan 1. Alur Pendistribusian

$\mathscr{W}_{4}=$ Dilakukan diluar Kantor POS 60000

\section{Proses Collecting}

Collecting merupakan tahap pertama dari aktivitas proses pendistribusian paket \& dokumen pada Kantor Pos Surabaya 60000. Proses collecting terdiri dari aktivitas pelanggan (pengirim) dalam mengirimkan paket maupun dokumen sampai diterima oleh Kantor Pos Surabaya 60000. 
Proses collecting atau pengumpulan dilakukan pada loket ritel Kantor Pos Surabaya 60000 serta Kantor Pos cabang Surabaya utara. Pada Kantor Pos 60000 terdapat 16 loket ritel yang digunakan dalam proses collecting pengiriman paket \& dokumen dan jumlah tenaga SDM yang bertugas dalam proses collecting pada loket ritel Kantor Pos Surabaya 60000 terdapat 16 petugas yang dibagi dalam dua jadwal dengan pembagian jadwal pagi dan sore, jadwal pagi dimulai pukul 07.00 sampai 14.00 WIB serta jadwal sore dimulai pukul 13.00 sampai 20.00 WIB.

Proses collecting pada Kantor Pos 60000 dimulai dengan menerima kiriman paket maupun dokumen dari pengirim, kemudian petugas loket ritel mengentri data kiriman ke dalam I-Pos (Integrated Postal Operations System) yang terdiri dari data tentang isi kiriman, berat kiriman dengan cara menimbang barang kiriman (paket \& dokumen) pada timbangan yang telah disediakan, alamat pengirim, alamat penerima, serta pilihan paket yang dipilih oleh pengirim (Paket Exspress, Paket Kilat Khusus, Paket Biasa), aplikasi I-POS adalah sebuah aplikasi berbasis web yang digunakan untuk proses transaksi pengiriman surat dan paket, kemudian petugas loket menutup mencetak resi kiriman dan menutup backsheet I-Pos kemudian petugas loket menyerahkan kiriman paket maupun dokumen ke puri terima Kantor Pos 60000 pada pukul 14.00 WIB maupun pukul 19.00 WIB sesuai jadwal kerja petugas loket ritel tersebut dengan membawa bukti serah kiriman atau yang biasa disebut dokumen manifest. Pada proses collecting petugas loket ritel membutuhkan waktu sekitar 3 menit untuk memproses satu paket maupun dokumen kiriman sedangkan untuk proses penyerahan kiriman dari Loket Ritel ke puri terima membutuhkan waktu 10 menit. Berikut merupakan alur proses collecting pada loket Kantor Pos Surabaya 60000.

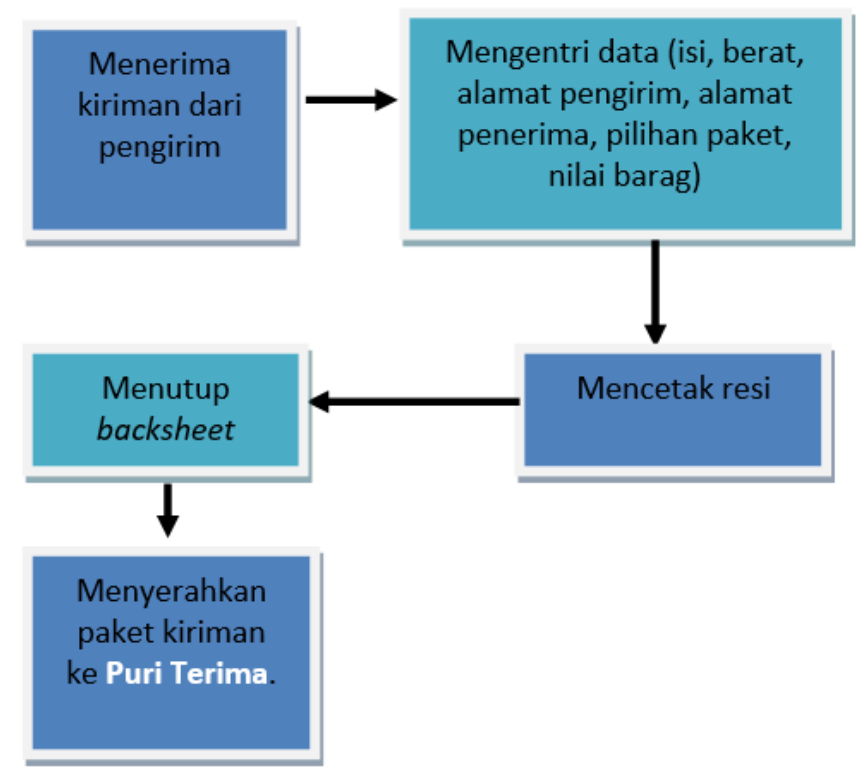

Bagan 2. Alur Proses Collecting 


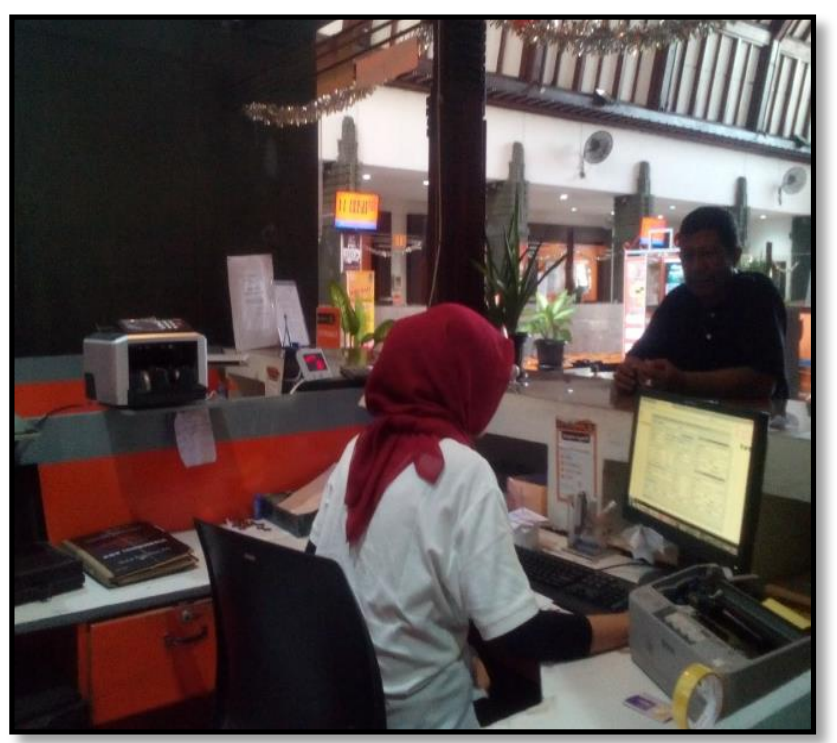

Gambar 2. Penganrian data pada loket POS Surabaya 60000

\section{KESIMPULAN}

Pembahasan tentang Proses distribusi dan optimasi paket dan dokumen pada Kantor Pos Besar Surabaya Utara 60000 dapat menyimpulkan beberapa hal, sebagai berikut :

- Prosedur pendistribusian dan pengiriman paket dan dokumen dalam negeri pada Kantor Pos Surabaya 60000 melewati empat tahapan yaitu proses collecting, processing (puri), transporting (processing centre), dan delivery.

- Proses Collecting dimulai dari penerimaan paket dan dokumen, kemudian pengentrian data ke software I-Pos, pencetakan resi, menutup backsheet, dan kemudian mendistribusikan ke Puri Terima.

- Proses Processsing (Puri) dilakukan scanning paket dan dokumen dari loket dan kantor pos cabang, memisahkan kiriman sesuai kota tujuan, mencetak manifest, dan memasukkan kiriman dalam kantong sesuai kota tujuan.

- Proses Transporting (processing centre) merupakan proses pemisahan dan sortiran berdasarkan kantong-kantong yang diterima dari proses sebelumnya di Puri.

- Proses Delivery dimulai dengan menerima kiriman paket \& dokumen dari PC Surabaya 60900, kemudian memisahkan kiriman sesuai dengan pool antaran yaitu dipisahkan sesuai dengan kecamatan, kemudian menscan kiriman paket \& dokumen untuk mengecek kesesuaian jumlah kiriman paket \& dokumen dengan manifest, kemudian memisahkan kiriman paket $\&$ dokumen sesuai dengan antaran yaitu sesuai dengan arah jalan dan posisi alamat penerima.

\section{DAFTAR PUSTAKA}

Fu, H., Youbei, H.\& Xuxu, W. (2007). Development of China C2C E-commerce from the perspective of goods delivery. The International Federation for Information Processing, $132,179-186$.

Giglio, J.M et all. (2018). "Integrating lifecycle asset management in the public sector".Business Horizons, Volume 61, Issue 4, July-August 2018, Pages 511-519.

Hayashi, Katsuhiko et all. (2018). "The Development of the Parcel Delivery Service and its Regulations in China”. Procedia - Social and Behavioral Sciences 125 ( 2014 ) 186- 198. 
SK DirJen HubDat 727/04. Keputusan Direktorat Jendral Perhubungan Darat Nomor 727/ AJ.307/DRJD/2004 tentang Pedoman Teknis Penyelenggaraan Angkutan Barang Umum Di Jalan.

Nakada, S., Ozawa, T., Azumi, T., Miyao, Y. \& Umemura, K. (1994). Report of the study on analysis of parcel delivery market. Institute for Posts and Telecommunications Policy.

Nemoto, T., Hashimoto, M., Ishihara, S., Hayashi, K., Saito, M., Takano, S, Sasaki, K., Kosaka, T, Oshima, N., Fu, Z., Nakaharai, S. \& Miyatake, K. (2012). Logistics Network planning in parcel delivery service. The Japan Research Center for Transport Policy.

Nohra Haddad, Matheus et all. (2018). "Large Neighborhood-Based Metaheuristic and Branch-and-Price For The Pickup and Delivery Problem With Split Loads". European Journal of Operational Research. Volume 270, Issue 3, 1 November 2018, Pages 1014-

1027.

Ouertani, Mohamed Zied, et al. (2008). "Towards An Approach To Select An Asset Information Management Strategy". International Journal Of Computer Science and Applications, 2008, vol. 5, no. 3 b.

PP 15/13. Peraturan Pemerintah No 15 tahun 2013 Standar Pelayanan untuk Layanan Pos Komersial.

Rofiah, Anik, et all. (2017). "Pengaruh Kualitas Pelayanan Terhadap Kepuasan Pelanggan pada PT. POS INDONESIA (PERSERO)". Prosiding Seminar Fakultas Ekonomi. Universitas 17 Agustus 1945. Samarinda.

Salim, Abbas, H.A (1993). Manajemen Transportasi. PT. Raja Grafindo. Jakarta.

Sasaki, N. (2006). "International parcel delivery service and logistics in East Asia". Transport Policy Studies, 8(4), 49-52.

Siringoringo, Hotniar et all. (2013). "Shopping Behavior of Indonesian Consumer Towards Imported Products". Procedia - Social and Behavioral Sciences. Volume 81, 28 June 2013, Pages 411-415.

Soemitro, R.A.A. \& Suprayitno, H. (2018). "Pemikiran Awal tentang Konsep Dasar Manajemen Aset Fasilitas". Jurnal Manajemen Aset Infrastruktur \& Fasilitas, Vol. 2, Sup.1, Juni 2018, Hal. : 1-13.

Tikno (2017). "Measuring performance of facebook advertising based on media used: a case study on online shops in Indonesia". Procedia Computer Science. Volume 111, 2017, Pages 105-112.

Tjiptono, F. \& Chandra, G. (2008). Service, Quality \& Satisfaction. Penerbit Andi.

Yogyakarta,

Wahyuningsih, Siti (2014). "Preferensi Konsumen Terhadap Jasa Pos di Yogyakarta". Jurnal Penelitian Pos dan Informatika, Vol. 4 No. 1 September 2014.

Zhang, Lei et all. (2018). "Simulation-based Assessment of Cargo Bicycle and Pick-up Point in Urban Parcel Delivery". Procedia Computer Science. Volume 130, 2018, Pages 1825 . 
(e)ISSN 2615-1847 (p)ISSN 2615-1839

Jurnal Manajemen Aset Infrastruktur \& Fasilitas - Vol. 3, No.1, Maret 2019 
(e)ISSN 2615-1847 $\quad$ (p)ISSN 2615-1839

Jurnal Manajemen Aset Infrastruktur \& Fasilitas - Vol. 3, No. 1, Maret 2019 